\title{
Methodology for Establishing Well-Being Urban Indicators at the District Level to Be Used on the CityScope Platform
}

\author{
Lisa Orii ${ }^{1,2, *}$, Luis Alonso ${ }^{2, *}$ and Kent Larson ${ }^{2, *}$ \\ 1 Computer Science Department and Philosophy Department, Wellesley College, Wellesley, MA 02481, USA \\ 2 MIT Media Lab City Science Group, Cambridge, MA 02139, USA \\ * Correspondence: lorii@wellesley.edu (L.O.); alonsolp@media.mit.edu (L.A.); kll@mit.edu (K.L.)
}

Received: 1 October 2020; Accepted: 30 October 2020; Published: 13 November 2020

check for check for
updates

\begin{abstract}
The MIT Media Lab City Science Group reshapes and reevaluates well-being as an emerging key indicator due the social challenges that cities are facing, such as inequality, police violence, and breaches to safety and security. Well-being in urban environments has been studied extensively, yet most research focuses on one aspect of well-being rather than multiple dimensions of well-being. Existing well-being indices that are used to compare well-being between different countries or to set a standards for well-being consider a variety of aspects that affect well-being, yet they are not specific to urban environments. When considering that no holistic and comprehensive research has been specifically conducted on well-being in urban environments, we research the relationship between the built features of an urban environment and well-being. In this paper, we propose a Well-Being Index composed of five urban indicators-Community Connectedness, Safety \& Security, Physical Health, Mental Health, and Diversity - which are each described by a set of urban attributes that enhance well-being. Each attribute is quantified using a calculation formula. In addition to quantifying well-being, the Well-Being Index emphasizes specific urban features that urban planners should consider for future decision-making. We apply the Well-Being Index to predict well-being in Boston, Massachusetts, and Kansas City, Missouri, and we speculate that Boston has higher levels of well-being in terms of the city's urban features. Based on our results, we provide suggestions for future choices in urban planning and design to improve the areas of well-being that we were able to identify with the Well-Being Index. We emphasize that the Well-Being Index can be applied to any city in the world, and can inform future decision-making for building urban environments through the CityScope platform; a novel methodology of interaction and collaboration by using a data-driven platform that simulates the impacts of interventions on urban ecosystems prior to detail-design and execution.
\end{abstract}

Keywords: well-being; urban planning; community; safety and security; health; diversity

\section{Introduction}

Nowadays, more than $55 \%$ of the world's population lives in urban settlements [1]. A remarkable amount of research has been conducted on urban environments, from the lenses of environmental science [2,3], health [3-5], and urban planning [6-8]. Many of these studies reflect the view that many cities endure challenges that are posed by environmental stressors and socioeconomic inequalities that consequently impact urban health and well-being. The complexities that are involved with well-being pose a great challenge for decision makers who lack tools and efficient metrics in order to assess and deliver efficient open governance. 
Since 2013, the MIT Media Lab City Science Group researchers have been developing CityScope, a human-centered, urban modeling, simulation, and decision-making platform. CityScope sits in the intersection of urban-planning, human-computer interaction, and social sciences to support an evidence-based discourse around the nature of the built environments [9,10] (Figure 1). The goal of the CityScope platform is to foster community engagement processes among a diverse group of stakeholders from government, industry, and academia, and civilians to make collaborative decisions while using the CityScope table [11-15]. Due to the social and political challenges that cities face, such as inequality, police brutality, and concerns that are related to safety and security, the MIT Media Lab City Science Group rethinks well-being in the context of these problems, and how the CityScope platform can initiate discussions that are related to well-being in the time we live in.

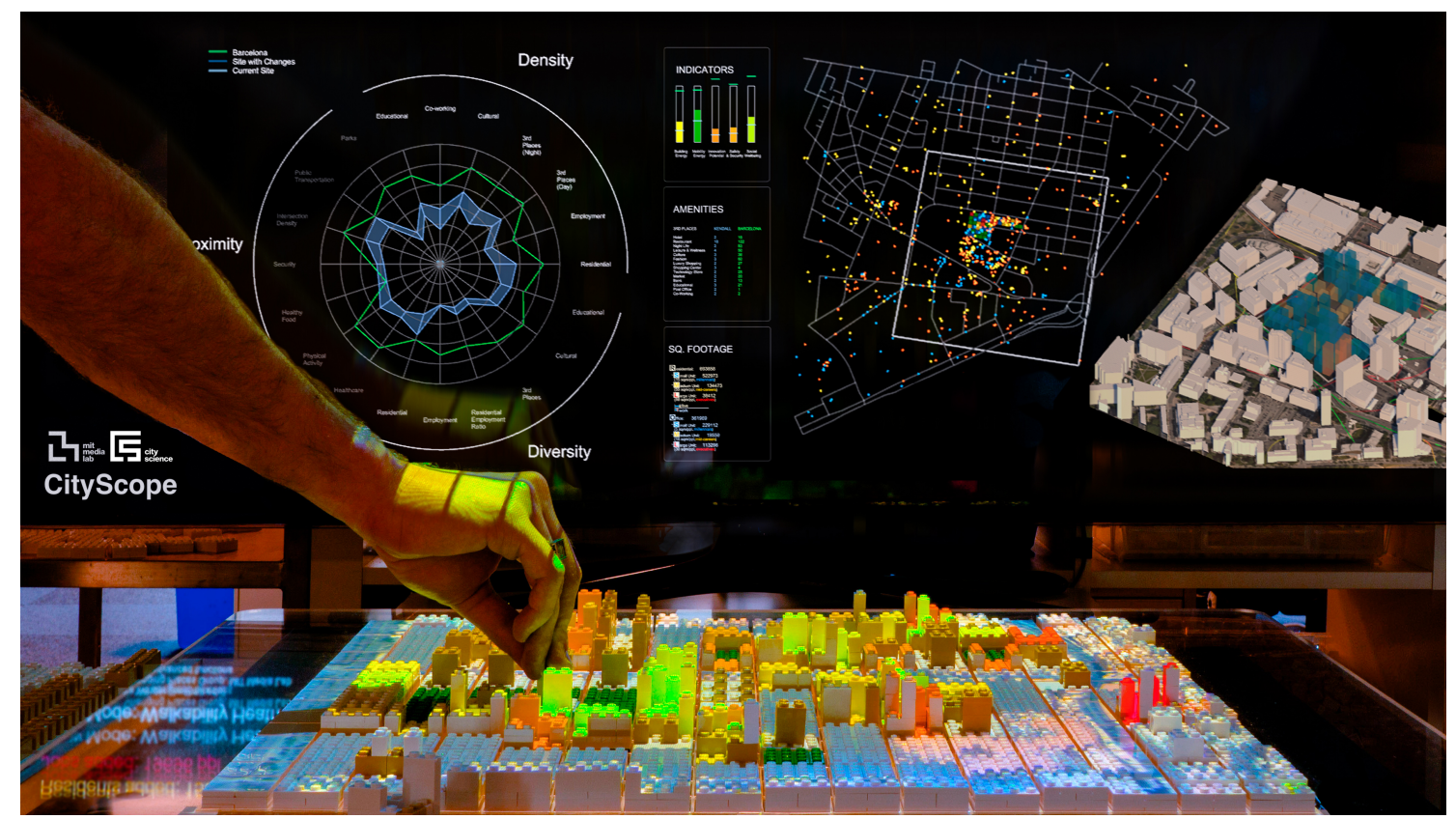

Figure 1. The MIT Media Lab City Science Group proposes a novel methodology of interaction and collaboration called CityScope, a data-driven platform that simulates the impacts of interventions on urban ecosystems prior to detail-design and execution. As stakeholders collectively interact with the platform and understand the impact of proposed interventions in real-time, consensus building and optimization of goals can be achieved. CityScope platform is composed of two layers: (i) computational (abstract) and (ii) tangible (physical).

\subsection{City Science Urban Indicators}

In this article, we outline the methodology behind urban well-being as an critical feature of the the urban indicators of the CityScope platform [16-18]. In the MIT Media Lab City Science Group, the urban indicators are used within the CityScope platform in order to measure the diversity and health of urban ecosystems. These urban indicators are expressed in the form of what we call the Radar Plot visualization tool, which is the mathematical visual that expresses the urban indicators on the CityScope platform (Figure 2). 


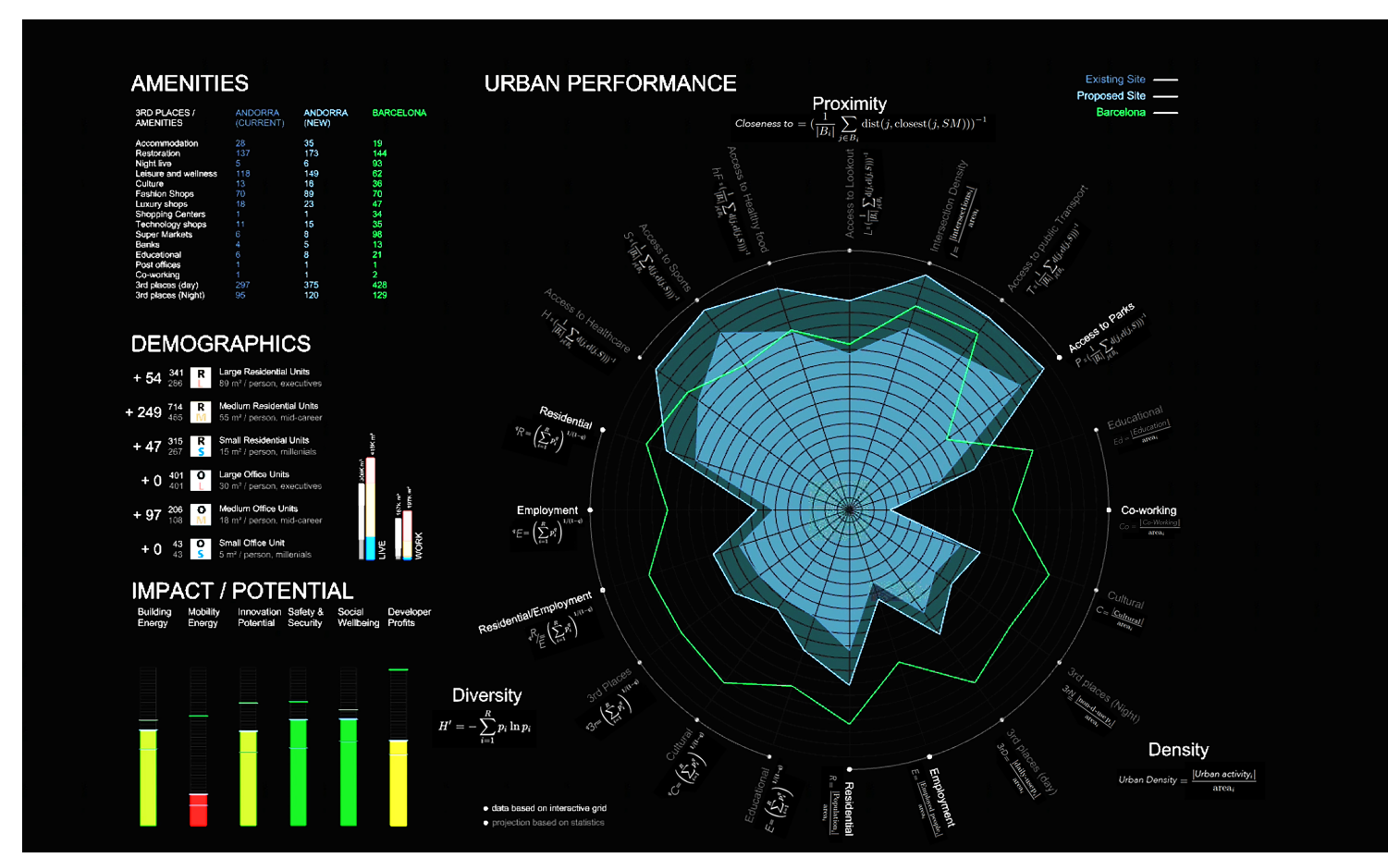

Figure 2. The radar plot is a visual tool that shows an aggregation of normalised indicators/attributes that are clustered in three different Dimension (Density,Proximity, Diversity. Note that sometimes, the radar shows also Energy as a dimension). This indicators or attributes can change depending on the avail-able data and the focus of the research question of each city or neighborhood. The inner shade (in blue in this figure) shows the urban performance of the area of study (a City, a Neighborhood, a District, a $1 \mathrm{~km}^{2}, \ldots$ ). The outer line of the radar means high performance ("good") of the indicator. The center of the radar shows low performance of the indicator ("bad"). The green line shows the benchmark or goals that the community wants to achieve with the urban intervention.

The Radar Plot indicates urban performance that is based on ratios between sub-indicators that are grouped under the Density, Diversity, and Proximity headings used to organize the characteristics of people and amenities in a neighborhood. In addition to the Radar Plot, bar-charts express the correlation between the diversity of urban attributes in order to express specific facets of the urban performance within a neighborhood [19]. Finally, heat-maps are used to geo-localize the urban performance characteristics over the three-dimensional interface.

Although the heat-maps is not the main subject of this article, it is worth mentioning that they are the most important visual output of CityScope. The heat-maps convert the raw and hard data from the Radar Plot and urban indicators into a comprehensive geolocated information map [20]. Most of the time, the expression of the ranking between "good and bad" urban performance is translated into a rank of colors between red and green, where red is "bad" and green is "good" (Figure 3).

Thanks to this "simplified" yet precise data visualization, CityScope becomes a multi-level data platform for community engagement, where technical and non-technical people can gather in otder to understand the impacts of their common decisions on the urban tissue [21]. 


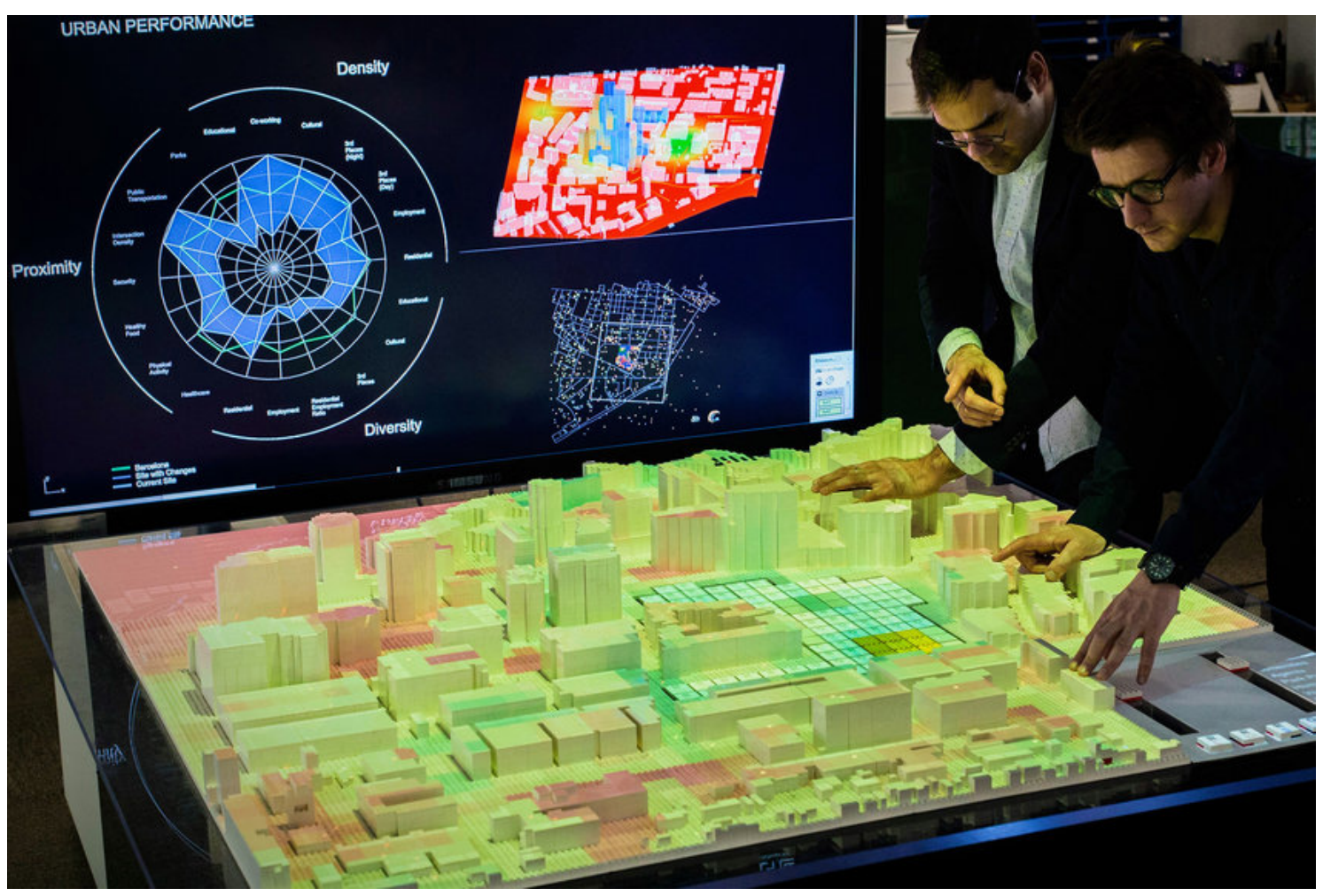

Figure 3. The CityScope platform makes both the physical structure and data layer of a city visible at once, and allows for users to interact with the computational analysis through a three-dimensional tangible interface. The platform enables users to view the urban environment as a multilayered space, in which overlays of data can be compared in real-time. This direct visual relationship between data and space allows for an intuitive comprehension of what would normally be a complex data set. The platform uses a screen and a tangible input table with projection mapping made with LEGO modules.

\subsection{Overview of Well-Being}

We first give a general overview of well-being and recognize that the multi-faceted nature of well-being allows for different approaches to understanding well-being [22,23]. Well-being, according to Merriam-Webster Dictionary definition, is in general the state of being happy, healthy, or prosperous, and it is a valuable facet of life and living, oftentimes affected by living situations and conditions. Well-being has been treated in many research fields, such as philosophy [24], social sciences [25], medicine [26], and psychology [27-29]. Most notably in the field of psychology, Maslow's Hierarchy of Needs [28] which was introduced by Abraham Maslow's publication Motivation and Personality, communicates how objective and subjective indicators of well-being satisfy various needs. Maslow postulated that people follow a pattern of recognition and satisfaction of needs. He also theorized that a person could not pursue a higher need in the hierarchy until the current need is satisfied. Maslow's Hierarchy of Needs is often displayed as a pyramid, where the bottom levels are survival needs and the needs relate more to self-actualization near the top. Mehan and Soflaei discuss the human needs in urbanism as synonymous to the needs in Maslow's Hierarchy of Needs, and translate such needs to the spatial qualities that are projected onto space designing [30]. For example, the spatial qualities in urban design that are associated with psychological needs are comfort, public services, firmness, and balance.

Well-being is typically categorized into two social indicators: objective and subjective [31]. Subjective indicators describe the ways in which people perceive and evaluate their lives and objective indicators describe the environments within which people live and work [32]. Diener et al. established four main components of subjective well-being: pleasant affect, unpleasant affect, life satisfaction, 
and domains satisfactions [33]. With these components, Diener and his colleagues developed the Satisfaction with Life Scale [29], which became the standard measurement of life satisfaction in the field of psychology. With this standard for measuring subjective well-being, recent research in psychology [27,33], medical science [26], and the social sciences [25,34] mainly draws upon data that were obtained from questionnaires that reflect people's subjective well-being. Typically, subjective well-being is based on social survey data and self-reported scores in response to questions such as "How satisfied or happy are you with your life?" [22,25,35]. Such surveys and scores have been used in understanding how the urban environment affects subjective well-being. Mao et al. distributed a self-report questionnaire for participants to rate their perceptions of the presence of environmental quality, namely architectural and urban planning aspects, sociorelational aspects, functional aspects, contextual aspects, and neighborhood attachment, using a seven point Likert-type scale [36]. Bonaiuto et al. conducted cross-cultural survey studies regarding the perceived quality of urban features at the neighbourhood level using a questionnaire that inquired architectural, social, functional, and contextual aspects [37].

Objective indicators are rooted in social statistics or hard data and is defined by material resources (income, food, housing, etc.) and social attributes (education, health, social network, etc.) [22,34]. The objective approach to well-being originates in welfare economics on measuring poverty and inequality, and its influence on individuals' fulfillment of life [31]. This approach is often used to inform national and international well-being indicators, such as the OECD's Better Life initiative [38], and Japan's proposed well-being indicators [39]. These frameworks attempt to measure societal development and quality of life while using standards of education, employment, health, income, social interactions, and safety. Defining objective well-being is considered a challenge due to the claim that objective well-being could be measured in terms of gross domestic product (GDP) [40]. However, well-being must reflect both material living conditions and the quality of life. Indeed, GDP per capita is found to have no correlation to life satisfaction [41], and, thus, differs from people's perceptions of their well-being, in other words, subjective well-being. Therefore, objective indicators, such as GDP, are weak indicators of societal and individual well-being.

Although most research has leaned towards measuring either subjective or objective indicators of well-being, we find that a thorough understanding of well-being is especially critical to a discipline, such as urban planning, which focuses on developing environments and building features that affect quality of life. Studies regarding well-being and urban environments describe or analyze parks or community gardens and general health [32,42-46], climate or environmental quality [47-49], and stressors in urban environments, such as noise [4,50,51]. In particular, research on parks and green spaces has received much attention and concludes that these spaces contribute largely to physical health and activity $[42-44,52,53]$. Aside from physical health, the relation of urban features to mental health has been extensively studied, mainly by observing the effects of parks or green spaces, community gardens, to mood and anxiety [42,54-60].

We also call attention to knowledge-based urban development (KBUD), which approaches urban development using a variety of knowledge management systems to advance the economy and society, in order to understand the theoretical frameworks for approaching well-being in urban environments. KBUD is based on the generation of knowledge-intensive goods and service production, which are considered as the driving forces of the global market and critical elements to globally competing cities [61,62]. A city that is successful in the competition between urban locations measured by knowledge creation, economic growth, and development, is known as a 'knowledge city', which encourages the generation of innovation, science, and creativity [63]. KBUD's humanistic perspective on development focuses on generating economic prosperity, social order, sustainable environment, and appropriate municipal governance [62], and its conceptual framework is established by the relations between four kinds of development, namely economic development, socio-cultural development, environmental and urban development, and institutional development [64]. Within the 
conceptual framework, each kind of development is founded on a set of indicators that are closely tied to personal well-being e.g., quality of life, cultural diversity, and personal safety.

\subsection{Review of Existing Well-Being Indices}

Although our research mainly focuses on urban environments in the United States, we also consider well-being indices that are developed by non-U.S. countries. The country level indices when combined, covers the main elements that define well-being, such as health, satisfaction, safety, and social interactions. We presume that countries identify different standards of well-being due to the differences in economic situations, geographic locations, and inequality levels. We study well-being indices from three countries, U.S., Japan, and Australia, and also review the internationally established well-being indices used for comparing well-being on a global scale, in order to capture a comprehensive and inclusive definition of well-being. We evaluate various global and national indices of well-being indicators, most of which combine objective and subjective indicators of well-being [31]. We select two global indices, namely the OECD Better Life Index [38] and the Global Youth WellBeing Index [65], in order to compare multiple countries' levels of well-being.

The OECD Better Life Index compares well-being across countries based on 11 topics that the OECD identify as essential to material living conditions and quality of life. The 11 topics are: housing, income, jobs, community, education, environment, civic engagement, health, life satisfaction, safety, work-life balance [38]. The Global Youth Wellbeing Index, an initiative of The International Youth Foundation, is specific to youth well-being, covers seven domains: gender equality, economic opportunity, education, health, citizen participation, safety and security, and information and communication technology [65]. In 2017, the Global Youth Wellbeing Index included 29 countries [65]. Scores for countries are on a 0 to 1 scale, with 1 being the highest [65]. The scores are chosen across the seven domains that are comprised of 35 indicators [65].

The national indices that we choose to observe which are national standards of well-being that are specific to a country, are Japan's Proposed Well-Being Indicators [39], the United States's Gallup-Sharecare Well-Being Index [66], Australian Centre on Quality of Life's Personal Well-Being Index-Adults [67], and European Social Survey (while the European Social Survey does not explicitly identify well-being indicators, we use this to understand how well-being is evaluated in Europe) [68]. The Gallup-Sharecare Well-Being Index sends survey invitations once per month, 12 months per year, to collect data on U.S. adults aged 19 years and older to evaluate participants perceive their well-being in five domains: purpose, social, financial, community, and physical [66]. The Gallup-Sharecare Well-Being Index has been used in research related to health and urban environments [69,70]. In Japan, the aegis of the Japanese national government's Cabinet Office established a Commission on Measuring Well-being in 2010 [71]. The proposed well-being indicators consist of three domains, with subjective and objective indicators for each domain: socio-economic status, physical and psychological health and social relatedness, and subjective well-being [39]. The Commission additionally considered sustainability as a conceptual domain [71]. A survey that was conducted in 2009 and 2010 helped establish five indicators of subjective well-being in Japan: subjective sense of happiness, ideal state of happiness, expected level of happiness in the future, sense of what is average, and emotional experience and gaps in well-being within households [71]. The Australian Centre on Quality of Life established a Personal Wellbeing Index (PWI) in 2013 with seven items of satisfaction where each item corresponds to a quality of life domain [67]. The seven items - standard of living, health, achieving in life, relationships, safety, community-connectedness, and future security-contribute to answering the question of how satisfied people are with their lives [67]. There exists PWI for adults (PWI-A), intellectual disability (PWI-ID), and school children (PWI-SC). 


\subsection{Research Objectives}

We struggled to find research that studied various features of urban environments in order to present comprehensive indicators that affect well-being. Additionally, while most urban planning research studied well-being in a manner that quantifies the residents' perspectives of their well-being through surveys or interviews, little research has provided concrete calculations or methodologies that predict how changes in urban environments affect well-being. We demonstrate an approach for predicting well-being in urban environments with quantified values. Our Well-Being Index is sensitive to the social settings of urban environments, and it avoids solely relying on traditional econometric indicators, such as income per household, which are less receptive of cultural contexts and values in international locations. We combine subjective and objective well-being indicators, so that, when a diverse group of people make urban planning choices using the CityScope platform, they can accurately comprehend the impact of their decisions. The Well-Being Index that we introduce can be used at the CityScope platform for the rapid assessment of urban policies that impact well-being aspects during community engagement process.

Referring back to Maslow's Hierarchy of Needs, we find that most past research findings contribute to understanding how the bottom levels of the hierarchy, namely Physiological, Safety, and Love \& Belonging, can be satisfied in urban environments. We attempt to expand how research that is related to urban planning and design treat well-being, and also consider how the Well-Being Index can cover higher needs in the hierarchy, namely esteem and self-actualization. Additionally, we build off of the KBUD framework that introduces elements of well-being in urban environments, and attempt to identify specific urban features that align with the indicators and developments that the framework outlines.

This study presents a holistic view of well-being by establishing a Well-Being Index that identifies urban features that contribute to well-being, and quantifies the impact of the urban feature on well-being. Our research presents the first of its kind to derive and apply numerical values of well-being as standards of comparison that can be used on the CityScope platform-an analytical support tool that is used to enable dynamic, iterative, and evidence-based decision-making between traditionally siloed stakeholders ranging from community members and government officials to domain experts. We go further and report well-being levels in Boston, Massachusetts, and Kansas City, Missouri as a potential use case for applying the Well-Being Index through CityScope. We use U.S. locations, which are well-known urban ecosystems to our research group, for the case study as a first step validation of the Well-Being Index, before we expand the breadth of the application of our work to international partners where validation can be more challenging. By providing these insights, we show how the Well-Being Index can provide predictions of well-being that can inform future urban planning and design processes to approach city building and place making from a human-centered perspective, that emphasizes the well-being on its residents.

In the next section, we explain the methodology that is used for establishing the urban indicators for well-being in our research, taking into account how well-being is measured by the various well-being indices that we introduced above.

\section{Methodology}

As mentioned, the goal of our research is to build a Well-being Index that merges subjective and objective well-being indicators in order to measure the impacts of urban ecosystems on well-being while using the CityScope platform. With this in mind, we looked into other fields of research, such as sustainability and ecology, where several effective methodologies for building new urban indicators have emerged. In this research we follow the recognized methodology by Gan et al. to build our urban indicators. Gan et al. introduces a review synthesis based on academic literature, international organizations, and research institutions, and selects and classifies methods for indicator weighting and aggregation [72]. 
In order to evaluate what indicators received the most focus in previous research, we first began by searching articles that are relevant to urban planning and well-being, and expanded our search based on the referred articles in the articles that we found. Our search was not limited to academic publications; we also referred to online sources and databases. We bring together the articles we found with the existing well-being indices, namely The OECD Better Life Index, Global Youth Well-Being Index, Japan's Proposed Well-Being Indicators, the Gallup-Sharecare Well-Being Index, and Australian Centre on Quality of Life's Personal Well-Being Index-Adults. For each existing well-being index, each article was categorized into the index's indicator(s) if any indicator was aligned with the findings from the article. This categorization was manually conducted upon reviewing: (1) title and abstract of the article, (2) findings presented by the article, (3) available keywords of the article, and (4) the entire article's text. Each time an article was categorized into the appropriate indicator, we accumulated the count to keep track of how many articles were categorized in the specific indicator. Once the categorization was complete, we compared the total number of articles across all of the indicators for one index. From this comparison, we focus on the three most popular indicators (the indicators with the most number of articles). The top three indicators for each well-being index as shown in Table 1 suggest that health, community or relatedness, and safety \& security are consistently significant indicators of well-being in past research. Using the information that we gathered, we selected and named five urban indicators to incorporate all of the indicators that our analysis deemed significant to well-being in urban ecosystems.

Table 1. The top three indicators classified with the most articles for all of the existing well-being indices.

\begin{tabular}{|c|c|c|c|}
\hline Well-Being Index & Top Indicator & Second Indicator & Third Indicator \\
\hline OECD Better Life Index & $\begin{array}{l}\text { Health, Environment } \\
\text { (tied with 1st) }\end{array}$ & Community & Safety \\
\hline Global Youth Well-Being Index & Health & Citizen Participation & Safety \& Security \\
\hline Japan's Proposed Well-Being Indicators & Relatedness & Health & Socio-Economic Conditions \\
\hline Gallup-Sharecare Well-Being Index & Community & Physical & Social \\
\hline Personal Well-Being Index-Adults & Health & Community & $\begin{array}{l}\text { Safety, Future Security } \\
\text { (tied with 3rd) }\end{array}$ \\
\hline
\end{tabular}

\section{Urban Well-Being Indicators in the Well-Being Index}

Here, we describe the five urban indicators we selected and named.

\subsection{Community Connectedness}

Community Connectedness is the degree to which a given area provides opportunities for social interaction and cohesion. This indicator emphasizes parks and green spaces as well as architectural street designs. We define Community Connectedness with five attributes: Perceived Safety, Park Coverage, Park Accessibility, Walkability, and Community Gardens.

\subsection{Safety $\mathcal{E}$ Security}

Safety \& Security is defined by people's evaluation of how safe and secure their environment is and objective features in urban environments that affect the judgements toward environments. We define Safety \& Security with three attributes: Perceived Safety, Park Coverage, and Use of Force Policies.

\subsection{Physical Health}

Physical Health includes attributes that either encourage physical activity or healthy food choices. We define Physical Health with four attributes: Perceived Safety, Community Gardens, Park Coverage, and Park Accessibility. 


\subsection{Mental Health}

Mental Health, which is oftentimes subjectively evaluated through social survey data and self-reported scores $[22,25,35]$, can be measured through the amount of exposure to nature, mental health support, opportunities for interaction, and perception of safety. We define Mental Health with four attributes: Perceived Safety, Park Accessibility, Social Interaction, and Community Gardens.

\subsection{Diversity}

Diversity refers to some variation in the distribution of characteristics among people [73]. Most of the existing well-being indices identify socio-economic conditions as an indicator that describes objective well-being indicators, such as income, housing, and education $[38,39,66]$. In the Well-Being Index, we attend to the variability of objective well-being, and take into account the various objective measurements of well-being while evaluating the diversity of those statistics. Hence, we call this indicator Diversity. We define Diversity with six attributes that are based on the categories of Diversity introduced by Boston Planning \& Development Agency (BPDA), formerly known as the Boston Redevelopment Authority (BRA) [74]: Diversity: Race and Ethnicity, Diversity: Income, Diversity: Age, Diversity: Language Spoken, Diversity: Education Level, Diversity: Region of Birth.

\section{Urban Attributes for Well-Being}

In this section, we outline all of the urban attributes and the way that we quantify their impacts on well-being.

\subsection{Perceived Safety}

Perceived Safety is the perception of comfort or level of risk and it differs from actual safety, risk, or crime [75]. For example, people often perceive alleys as unsafe, although actual crime rates in alleys are low [76]. Perceived Safety can be affected by the physical features of an environment, such as light, open space, and access to real refuge [77]. Additionally, much research has been conducted with regard to public parks and feelings of safety [78]. More specifically, the perception of safety from crime was largely found to be influenced by the presence of law-enforcement, sufficient lighting, and presence of homeless people who use parks as living spaces [78-82]. Perceptions of safety from injury were related to the presence of heavy traffic, rocks, and debris $[78,80,83]$.

Perceived Safety is often considered of paramount importance to all forms of activity, a prerequisite of well-being, good health, and high quality of life [84,85]. High levels of Perceived Safety encourage a sense of security and confidence, participation in physical activity in people's neighborhoods, and social interaction [86]. This attribute is especially important to Physical Health because Perceived Safety is a precondition of physical activity $[86,87]$. Studies show that adolescents who perceive their neighborhood as safe, report better general health [88], are more likely to participate in physical exercise [89], and are less likely to have longstanding illnesses [90].

The Perceived Safety of the built environment strongly impacts the Mental Health of individuals. Stafford et al. found that the fear of crime was associated with poorer Mental Health and lower quality of life [91]. Davidson et al. investigated consequences of street harassment, including perceptions of safety and anxiety among college women. They found that lower levels of Perceived Safety in busy public settings and isolated public settings were associated with higher levels of anxiety [92]. Research has also demonstrated that Perceived Safety directly impacts Mental Health, because it largely affects an individual's self-regard $[93,94]$. Further, the perception of safety is positively associated with Mental Health, where physical activity and social cohesion mediate this relationship [95].

In order to measure this attribute, we retrieve data pertaining to Perceived Safety from Numbeo, an online database of user contributed data about cities worldwide [96]. In addition to quantified values that inform Perceived Safety, Numbeo provides updated information on world living conditions, including the cost of living, housing indicators, health care, traffic, and pollution. Numbeo has agreed 
to share with the MIT Media Lab City Science Group their API for access to their data. Perceived Safety is difficult to predict solely with urban spatial qualities, and so we refer to Numbeo's accessible data that are based on answers to surveys for our research. Numbeo's data provide information about both country-wide and city-wide perceptions of safety and crime. For the purposes of our research, we select city data in order to understand Perceived Safety on the smallest scale possible i.e., city scale using Numbeo. Numbeo Crime Index designates a number from 0 (minimum) to 100 as an estimation of the overall level of crime in a given city or a country. The Crime Index scores are based on survey results that reflect respondents' concerns or worries about being affected by crime. Crime Index scores that are lower than 20 are very low, scores between 20 and 40 are low, scores between 40 and 60 are moderate, scores between 60 and 80 are high, and scores higher than 80 are very high. Numbeo Safety Index, on the other hand, is the opposite of the Crime Index; if a city has a high Safety Index, then the city is considered to be very safe. Numbeo uses the Java programming language to process the survey results and generate Crime/Safety Index scores. We utilize the data from the Safety Index for our purposes of understanding Perceived Safety.

\subsection{Park Coverage}

Previous research has found that urban Park Coverage was positively associated with community well-being and enhanced the sense of engagement people have with the places where they live [43,97-99]. High Park Coverage can aid in constructing social capital, increasing perceptions of community well-being and perceptions of quality of life, facilitating neighborhood satisfaction, and fostering community attachments [43,99-101]. Additionally, Park Coverage is strongly correlated to improving perceptions of safety. Large grass fields, long view distances, and increased trees are found to increase the perceptions of safety $[54,102]$. While increased trees can increase perceptions of safety, it is important that the trees and grass are well-maintained [97,98].

We measure Park Coverage by the following equation [103]:

$$
\text { Park Coverage }(\%)=\frac{\text { parkland }}{\text { cityarea }} \times 100
$$

The Trust for Public Land calculates Park Coverage while using data that were collected in an annual survey by The Trust for Public Land's Center for City Park Excellence [103]. Using census-defined urban areas to identify where to collect and create data for cities, towns, and communities, the Trust for Public Land obtained geographic boundaries from the U.S. Census 2010 Places geospatial dataset and population estimates from ESRI's 2018 Demographic Forecasts. We refer to the ParkScore they provide to rank Park Coverage scores in our case study.

\subsection{Park Accessibility}

Park Accessibility is the accessibility of a park from a given location. Parks that are largely free and accessible could provide opportunities for social interaction between people [104]. Other studies found that the association between green space and supportive interactions had less to do with actual contacts with neighbours and more to do with the green space's ability to strengthen the sense of community via place attachment and identity $[105,106]$.

Past research suggests that neighborhoods that are near green spaces in urban areas promote physical activity $[107,108]$. The benefits that arise form this kind of physical activity in natural environments i.e., 'green exercise' is found to extend beyond the physical benefits of physical activity and actually increase savings in health services by ameliorating required treatment [54,109]. Green exercise, in addition to promoting physical health, has positive influences on mental health, self-reported health, and mood and self-esteem [42,55-59]. A study that was conducted by Carter and Horwitz revealed that, while all respondents discussed their use of green space for physical activity, they spoke more about how being in green spaces made them feel [56]. One respondent acknowledged that being in a green space is essential for emotional and psychological health, and another answered 
that being in green spaces enhances relaxation, and hence a sense of well-being. As a result, people who experience the presence of green spaces perceive their general health and mental health better [110]. Additionally, green spaces have the potential to mitigate pollution and, therefore, support health [110].

We consider the proximity to a park in terms of the how reachable it is within a given time limit in order to measure this attribute. Research shows that the median distance and duration of waking trips among walkers are 0.5 miles and $10 \mathrm{~min}$ [111]. When considering these data, we consider a park to be very accessible if it can be accessed within a $10 \mathrm{~min}$ walk, which roughly estimates a distance of 0.5 miles. The accessibility score at each location, given by the equation below, is computed by summing the capacities of the reachable places. The accessibility to any type of point of interest from any location is articulated below [112].

$$
A_{n}^{x}=\sum_{p \in P_{n}^{x}} C_{p}
$$

$A_{n}=$ Accessibility of places of interest of type $x$ from location $n$

$P_{n}^{x}=$ Set of places of interests of type $x$ which are reachable within a 10 min walk from location $n$ $C_{p}=$ Capacity of point of interest $p$

For each goal point of interest, the overall accessibility score is found by averaging the accessibility across all of the applicable places of interests.

We refer to the Trust for Public Land Park ParkScore Index, which provides a normalized score of Park Accessibility between 0 and 100. For each park studied, a 10-min walkable service area was created and analyzed in order to identify physical barriers to walking [103]. Using the 10-min walk service areas, overall access statistics were generated for each point of interest.

\subsection{Park Quality}

Larson et al. analyzed data from over 100 cities in the United States and found that Park Coverage was among the strongest contributors to overall well-being and that residents reported higher levels of well-being with greater Park Coverage in their cities [70]. However, other research suggests that the Park Quality is at least as important as Park Coverage and Park Accessibility in encouraging physical activity [113].

We introduce the equation for calculating Park Quality, which is informed by The Trust for Public Land [103].

$$
\text { Quality }=\frac{\sum_{i \in n} \frac{a_{i}}{\text { capita }}}{n}
$$

$a_{i}=$ Amenity

$n=$ Total number of key amenities

We refer to The Trust for Public Land Park ParkScore Index, which measures Park Quality by awarding points for the availability of six key park amenities on a per capita basis [103]. The six key park amenities are also outlined by The Trust for Public Land Park ParkScore Index: basketball hoops, off-leash dog parks, playgrounds, recreation and senior centers, restrooms, splashpads, and spraygrounds [103].

\subsection{Walkability}

Walkability is based on the distance to amenities. The relationship between walking or Walkability and social interactions have been the subject of various studies [114]. Walkability includes accessibility to third places, which are places that foster communication networks and community outside of first and second places $[115,116]$. Examples of third places include shops, restaurants, community centers, places of worship, plazas and parks, and malls, markets, and beauty salons [116]. If there are more opportunities for social interaction and social activities, the chances for developing long-lasting and caring connections are greater $[43,115]$. Research suggests that streets that are designed for 
walking and cycling promote social interactions, which, in turn, enhances mental and physical health, because walking can increase the chance of incidental social encounters [43]. A case study in Montreal, Canada demonstrated that walking is a strong predictor of social participation by the elderly [117].

The Walk Score website rates the Walkability of neighborhoods on a 0-100 scale, based on pedestrian friendliness and walking routes to destinations such as grocery stores, schools, parks, restaurants, and retail [118]. A growing number of research suggests that Walk Score is a valid measure for estimating Walkability [119-121].

\subsection{Community Gardens}

Community Gardens are community spaces that help to foster social interactions [43]. Bartolomei et al. researched the social role of Community Gardens in Sydney, Australia, and confirmed that the contributory role of Community Gardens in strengthening social interaction [122]. Community Gardens are based in a sense of community, where participation and involvement allow for a wide range of participants to share tools and responsibilities and, as a result, foster relationships over time [123,124].

Community Gardens enhance the accessibility to better nutrition and healthier food and promote physical activity $[44,125]$. In one study in West Hollywood, students participating in community gardening reported that the frequency of physical activity and the consumption of fruits and vegetables have increased [44]. The health benefits of Community Gardens extend beyond the promotion of physical activity and access to healthy food, and they have been found to decrease the likelihood of contracting mental illnesses $[45,52,126,127]$. The participants of Community Gardens indicate that the reasons for their participation include access to fresh and better tasting food, enjoyment of nature, and better Mental Health [53]. Gardening has the effect of reducing stress, as measured by self-reported mood and salivary cortisol levels, which act as biomarkers for variation in stress levels [128,129].

We establish the following equation, which calculates the number of Community Gardens per 1000 residents:

$$
\frac{\text { number of community gardens }}{\text { population }} \times 1000
$$

The value of this attribute is normalized on a $0-100$ scale by deriving the rank percentile of the value based on the available data of 69 cities in the U.S that were gathered by The Trust for Public Land in 2019 [103].

\subsection{Use of Force Policies}

With recent surges in activism for Black Lives Matter and protests against police brutality, the presence of police have become controversial [130-132]. The Police Use of Force Project examines eight Use of Force Policies that have been studied and shown to decrease the number of killings by the police, as shown in Table 2. According to Mapping Police Violence, a research collaborative that collects data on police killings in the U.S. in order to quantify the impact of police violence, police killing is a case where a person dies as a result of being "shot, beaten, restrained, intentionally hit by a police vehicle, pepper sprayed, tasered, or otherwise harmed by police officers, whether on-duty or off-duty" [133]. The Police Use of Force Project found that police departments that enforced four or more of the policies had the fewest killings per population and per arrest. A police department that has all eight policies in place has $72 \%$ fewer killings than a police department with none of the policies [134]. Although the enforcement of Use of Force Policies will not resolve police brutality, we recognize that it is one step toward building a society that respects marginalized and vulnerable groups, and contributing to social change. 
Table 2. Use of Force Policies that are associated with fewer police killings.

\begin{tabular}{lc}
\hline Policy & Percent Fewer Killings Per Capita with Each Policy in Place \\
\hline Requires comprehensive reporting & 25 \\
Requires the office to exhaust all other measures before shooting & 25 \\
Bans chokeables and strangleholds & 22 \\
Has use of force continuum & 19 \\
Requires de-escalation & 15 \\
Duty to intervene & 9 \\
Restricts shooting at moving vehicles & 8 \\
Requires warning before shooting & 5 \\
\hline
\end{tabular}

We weigh each of the policies based on the policy's impact in terms of percent change in killings by police in order to quantify this attribute. We establish the following equation:

$$
\text { Impact of Use of Force Policies }=\frac{\sum_{p \in n} p_{\text {percent }}}{\sum_{j \in m} j_{\text {percent }}} \times 100
$$

$p=$ The implemented Use of Force policy

$p_{\text {percent }}=$ Percent fewer killings per capita associated with the implemented Use of Force Policy $p$

$n=$ Set of all implemented Use of Force Policies

$j=$ The Use of Force Policy

$m=$ Set of all Use of Force Policies that can be implemented

This calculation does not represent the accurate percent change of police killings when certain policies are enforced. Instead, we measure the potential impact that each policy can bring to decreasing police killings. The maximum importance possible is the sum of all of the percentages across the eight policies. We sum the relative importance of each policy implemented with respect to the sum percentage, and then derive how the implemented policies could decrease police killings.

\subsection{Social Interaction}

Social Interactions contribute to Mental Health and mitigating depression [135]. Socialization can enhance connection and caring, increase perceptions of safety, and decrease feelings of loneliness and isolation, all of which are linked to positive Mental Health [86].

Social Interaction is equivalent to the composite score of Community Connectedness indicator, because this indicator expresses how much an urban environment fosters opportunities for Social Interaction. We calculate this while using min Equation (7), which is discussed in a later subsection.

\subsection{Diversity}

Diversity: race and ethnicity is defined by the variety of ethnic and racial groups within a specific area. We use the six categories defined by the U.S. Census Bureau, which are: White, Black or African American, American Indian and Alaska Native, Asian, Native Hawaiian and Other Pacific Islander, Some other race [136].

Diversity: income is the variance in household income within a given area. We define three main categories: households with annual incomes of less than $\$ 35,000$, households with annual incomes between $\$ 35,000$ and less than $\$ 100,000$, households with annual incomes that are greater than $\$ 100,000$.

Diversity: age is the variation in ages of the residents in a location. We define four main groups: residents under 20 years of age, residents between 20 and 34 years of age, residents between 35 and 64 years of age, and residents over 65 years of age.

Diversity: language spoken is the variability of languages spoken at home by residents of a specific area. We use the five categories established by the U.S. Census Bureau: only English, Spanish, Other Indo-European languages, Asian and Pacific Island languages, and Other [136]. 
Diversity: education Levels is the variety of levels of educational attainment of the residents in a specific geographic area. We identify three categories: people without a high school diploma or GED equivalency, people with a high school diploma or GED equivalency or some college (no degree) or associate's degree, people with a bachelor's degree or higher. These categories are limited to residents of 25 years or over.

Diversity: region of birth is defined as the plurality in the region of birth of a population in a given area. We use the four categories outlined by the U.S. Census Bureau: residents born in state, residents born out of state, residents outside of the U.S. (Puerto Rico or U.S. Island Areas or born abroad of American parents), residents born in foreign countries [136].

The calculation used for measuring Diversity in each of the six aspects is [74]:

$$
\text { Diversity }=1-\sum p^{2}
$$

$p=$ Probability of coming across someone with this characteristic

For example, if we were to calculate Diversity: Race and Ethnicity, which determines how diverse a given area is in terms of race and ethnicity, then $p$ is the percentage of a particular race or ethnicity that is represented in a given population. If half of the population were white, then $p=0.5$. The cumulative sum of all the probabilities are subtracted from 1, representing the idea of coming across someone different. The score is normalized to a 100-point scale and it is performed for each of the six Diversity attributes, and eventually combined in order to create a composite Diversity score.

\section{Composite Scores}

In order to measure importance, we use equal weighing [72,137], the most common aggregation scheme for calculating composite scores for each indicator, and eventually for the composite well-being score. Equal weighing recognizes the equal status for all sub-indicators and is used when there is little statistical or empirical evidence that supports a different strategy [138].

In order to calculate a composite score, we aggregate over all of the normalized input variables (in this case, attributes for calculating composite indicator scores and indicators for calculating a composite Well-Being score). We use the weighted arithmetic average described below [72].

$$
\text { Score }=\sum_{i=1}^{n} w_{i} x_{i}
$$

$n=$ Total number of input variables

$w=$ Nominal weight assigned to the $i$-th variable

$x=$ Normalized score of input variable $i$

For the purposes of our study, we set $w=1$ to conduct equal weighing. We normalize the composite score on a 0-100 scale.

\section{Case Study Comparing Boston, MA and Kansas City, MO}

We predict that the outputs of the Well-Being Index will reflect the extreme differences between the urban ecosystems. We remain agnostic about the governance structures or politics that are embedded into the two urban environments in order to focus on the peripheral urban features that are present. After computing the scores for attribute, we normalize the values between 0 and 100 rounded to the nearest hundredth place, as presented in Table 3. Using Equation (7), we calculate the composite scores of the five indicators and normalize the outputs so the sores are between 0 and 100. The results of well-being according to the attributes and indicators we propose are displayed in Table 4 . The data that we use are easily accessible in that all data can be found through online sources. 
Table 3. Normalized scores between 0 and 100 of attributes relevant to the Well-Being Index for Boston, MA and Kansas City, MO.

\begin{tabular}{lccc}
\hline Attribute & Boston, MA & Kansas City, MO & Data Source \\
\hline Perceived Safety & 64.48 & 41.06 & Numebo Safety Index [96] \\
Park Coverage & 90 & 54 & The Trust for Public Land [103] \\
Park Accessibility & 100 & 47.5 & The Trust for Public Land [103] \\
Park Quality & 65.17 & 35 & The Trust for Public Land [103] \\
Walkability & 82 & 52.17 & Walk Score [118] \\
Community Gardens & 66.67 & 0 & The Trust for Public Land [103] \\
Use of Force Policies & 96.09 & 45.25 & Use of Force Project [134] \\
Social Interaction & 80.63 & 46.95 & Community Connectedness indicator composite score \\
Diversity: Race and Ethnicity & 55.38 & 64.74 & U.S. Census Bureau [136] \\
Diversity: Income & 65.50 & 72.26 & U.S. Census Bureau [136] \\
Diversity: Age & 71.26 & 24.49 & U.S. Census Bureau [136] \\
Diversity: Language Spoken & 55.73 & 55.84 & U.S. Census Bureau [136] \\
Diversity: Education Level & 58.34 & 57.41 & U.S. Census Bureau [136] \\
Diversity: Region of Birth & 66.96 & &
\end{tabular}

Table 4. Composite Well-Being scores for Boston, MA and Kansas City, MO.

\begin{tabular}{lcc}
\hline Indicator & Boston, MA & Kansas City, MO \\
\hline Community Connectedness & 80.63 & 45.25 \\
Safety \& Security & 83.52 & 28.35 \\
Physical Health & 80.29 & 47.81 \\
Mental Health & 77.95 & 48.12 \\
Diversity & 62.20 & 56.62 \\
\hline
\end{tabular}

\section{Results}

According to the Well-Being Index, we find that Boston has a higher level of well-being in comparison to the well-being of Kansas City, as shown in Table 4. Across all five urban indicators that compose the Well-Being Index, Boston has higher scores than Kansas City. Further, all but one attribute score is higher in Boston than Kansas City (Table 3). The stark differences in scores across the attributes contribute greatly to the variance in indicator scores between the two cities.

Boston has an evidently higher score in Community Connectedness than does Kansas City. Observing the six urban attributes that contribute to this indicator, we find that the scores for each attribute for Kansas City are significantly low. Here, we focus on Park Coverage, Park Accessibility, and Walkability, which are the three urban attributes that present the most noticeable differences between Boston and Kansas City. Boston is ranked ninth and Kansas City is ranked thirty-second, according to ParkScore by The Trust for Public Land [103]. Boston has much higher values across the all three park attributes i.e., Park Coverage, Park Accessibility, Park Quality than does Kansas City. The most noticeable difference between the scores for Boston and Kansas City with respect to the park attributes, is evident in the scores for Park Coverage and Park Accessibility. With regard to Park Accessibility, Boston exhibits an impressively high score as $100 \%$ of its residents live within a 10-min walk from a park, while only $70 \%$ of Kansas City residents live within the same walking distance [103]. The Trust for Public Land also provides accessibility comparisons between age, income, and race. Boston has $100 \%$ accessibility for all categories of age, income, and race while the accessibility varies greatly, depending on age, income, and race in Kansas City [103]. However, given that the national average of Park Accessibility is 55\%, we consider both Boston and Kansas City to have relatively high accessibility to parks. Interestingly, while Boston's median park size is extremely small in comparison to other park size in the U.S., including Kansas City, the vast number of parks in Boston (930 parks) accumulate to a greater score for Park Coverage [103]. On the other hand, Kansas City has the maximum score for its median park size, but its number of parks is roughly half of the number of parks (471 parks) in Boston [103]. 
By observing the scores, we procured from the calculations for each of the three urban attributes of Safety \& Security, we recognize that Kansas City has a significantly low score, because of its low score in the attributes Use of Force Policies and Park Coverage. As of October 2020, Boston Police Department has in place seven Use of Force Policies, where the unenforced policy is the requirement for comprehensive reporting [134]. Kansas City Police Department is the only police department of America's largest 100 police departments that does not have a single Use of Force Policy enforced [134]. Given this information, we predict that if Kansas City Police Department arranged for a combination of Use of Force Policies to be implemented and changed policy practices, then this change could consequently improve the score for Safety \& Security. Additionally, from January 1, 2013 to December 31, 2019, 12 and 28 people have been killed by the police in Boston and Kansas City, respectively; nine of the killings by the Boston police and 17 of the killings by Kansas City police were Black [133].

Further, there is a notable difference in the Perceived Safety scores between Boston and Kansas City, which influence the composite scores for several urban indicators in the Well-Being Index. We draw conclusions about Perceived Safety with regard to each city from Numbeo, which calculates crime and safety based on perceptions of website visitors gathered through surveys from the past 36 months. Numbeo uses data from 143 website visitors (September 2020) to measure crime and safety in Boston and 67 website visitors (July website) to do the same in Kansas City [96], and we recognize that there is a limitation to collecting accurate data due to the sample size.

We find that Diversity is the only urban indicator in which the scores of Boston and Kansas City are comparable. Diversity: Age is the only urban attribute out of all urban attributes in the Well-Being Index, where Kansas City has a higher score. We also take note of the similar scores for Diversity: Income.

\section{Discussion}

First, we highlight the results at the methodological level in order to emphasize that the Well-Being Index is a scalable tool that informs decision-making. Next, we propose that the Well-Being Index can be used in any city in the world, given that the data is available and accessible. Lastly, we discuss how the findings from the case study and from the Well-Being Index in a broader context, can be extended to identify shortcomings in current built environments, and can help to inform future decision-making to enhance well-being.

\subsection{Application of the Well-Being Index to CityScope}

The Well-Being Index does not depend solely on objective indicators of well-being, such as income, food, and healthcare. While these measurements are easily attainable, they alone do not capture the various features that affect well-being in urban environments. Instead, we combine subjective and objective indicators of well-being to illustrate a holistic view of well-being and to allow for a diverse group of decision makers to make future choices for urban planning and design while using the CityScope table. Our holistic approach to well-being can be deployed and used by the City Science Network of Collaborative Cities, which is a network that gathers the urban knowledge and challenges in cities across four continents to collaboratively discuss global and individual solutions [139]. The Well-Being Index can be used for the CityScope platform for the rapid assessment of urban policies that impact well-being, and simulate community engagement processes enabled by the City Science Network of Collaborative Cities.

\subsection{Informing Future Choices for Urban Planning and Design}

The Well-Being Index identifies areas of improvement in urban environments through the scores that it generates for each of the five urban indicators. For example, a low score in Physical Health indicates that, currently, the urban environment lacks strong urban attributes of Physical Health that influence well-being. From this, urban planners and designers can deliberate ideas for augmenting the urban attributes that contribute to Physical Health. Below, we provide recommendations for future 
choices in urban planning and design that focus on improving the urban features we identify in the Well-Being Index.

\subsubsection{Perceived Safety}

Perceived Safety is an omnipresent attribute in the Well-Being Index, and elevating Perceive Safety could significantly improve multiple urban indicator scores and as a result, the composite well-being score. Perceived Safety is based on the levels of comfort that people attain through their lived experiences and, thus, Perceived Safety levels vary between individuals. Yet, we incorporate Perceived Safety as one of the urban attributes to consider how living conditions and surroundings largely influence the perceptions of neighborhoods and environments. We suggest urban planners and designers revisit the built features of an environment and their qualities to reconsider how Perceived Safety could be increased. Streets or areas that feel unsafe due to dim lights or a lack of street lamps should be reviewed and improved accordingly to allow for more activity and continued usage of facilities such as parks or outside sports areas [79,83]. Playground and park designs that are considerate of their distances from heavy traffic streets can significantly improve Perceived Safety if these gathering areas are distanced from busy streets $[78,79]$.

\subsubsection{Use of Force Policies}

Enforcement of Use of Force Policies can not only decrease police killings but also help civilians feel safer than they are now upon encountering the police. Land-use regulations and how police inhabit space should be reconsidered alongside when considering the implementation of Use of Force Policies; these changes could affect Perceived Safety and Safety \& Security at large.

\subsubsection{Parks}

In order to explain improvements of park attributes, namely Park Coverage, Park Accessibility, and Park Quality, we return to the case study. Given that Boston has a small median park size but an impressive number of parks spread throughout the city, we suggest Boston could benefit from urban planning and design choices that focus on expanding median park size. On the other hand, we find that Kansas City has an exceptional median park size, but it has much fewer parks, and so we propose that Kansas City could benefit from increasing the number of parks. Further, if urban planners consider the spread of parks then this could consequently improve the Park Accessibility of the city. Thus, depending on the situations of parks in the current environment, the approach to improving its parks attributes may differ. We recommend that urban planners and designers first determine the current number of parks and median park size to devise a strategy for improving overall Park Coverage. As a result of an effort to enhance Park Coverage, improvements in other urban attributes, such as Park Accessibility may follow.

\subsubsection{Walkability}

We measure Walkability through the two aspects of pedestrian friendliness and walking routes to destinations. Urban planners and designers should consider how either or both of pedestrian friendliness and walking routes to destinations can be enhanced with future choices in order to improve the Walkability of a given area. For example, retail, lobbies, or events that have the potential for large gathering, should be placed strategically along walking routes to attract and engage the public. Additionally, the width of walkway paths can be another factor to consider. Previous research shows that sidewalk width is a prerequisite for supporting other street characteristics or features that can enhance stationary social interactions and feelings of inclusiveness and participation $[30,140]$. Thus, future place making should focus not only on establishing accessibility and walkable places, but also on designing walkways that can be used safely for social gatherings. 


\subsection{The Well-Being Index in the Context of Maslow's Hierarchy of Needs}

We explained earlier that most past research contributes to understanding how the bottom levels of the hierarchy, namely physiological, safety, and love \& belonging, can be satisfied in urban environments. We evaluate whether the Well-Being Index is able to account for the higher needs in the hierarchy, namely esteem and self-actualization, in addition to the needs in the bottom levels of the hierarchy.

The Well-Being Index adequately covers physiological needs by considering basic survival necessities in urban environments with accessibility to food with the attributes Community Gardens and Walkability (to grocery stores) and, more broadly, the urban attributes of the Physical Health indicator. The next level in the hierarchy is safety, which is fully accounted for in the Safety \& Security urban indicator of the Well-Being Index. The Well-Being Index considers love \& belonging needs specifically with Social Interaction and other urban features that enable this need, such as Perceived Safety, Park Coverage, Park Accessibility, Walkability, and Community Garden. Esteem, which is defined by respect, status, strength, and freedom, is empowered through Community Connectedness. In addition to the urban attributes of Community Connectedness, civic participation or engagement can augment esteem by strengthening the community's voice and participation in decision-making. This is considered for in the Well-Being Index itself, and the CityScope platform that allows for diverse stakeholders to collaboratively make decisions. Further, enforcing Use of Force Policies and meeting the demands of justice and respect for the lives taken due to police brutality are practical courses of action that can be taken to enhance the respect and recognition of residents' well-being. Perceived Safety, which largely influences an individual's self-regard, in turn affects Mental Health [93,94]; thus Perceived Safety is essential to satisfying esteem needs. Lastly, self-actualization is the most difficult need of all to satisfy, but the consolidation of all the urban indicators that we present in the Well-Being Index can advance opportunities for reaching full potential. Specifically, an establishment of policies and support systems that focus on Mental Health can assist in allowing for creativity, pushing past challenges, and seeking personal growth. In addition to the KBUD framework that recognizes cultural diversity as an indicator that belongs to socio-cultural development [64], research has found that Diversity enhances community well-being and conditions that enable people to live together and that there is a significant relationship between the well-being of a society and tolerance towards diverse groups that exist within the society [141,142]. In this view, Diversity in the context of Maslow's Hierarchy of Needs, is a spatial quality that aids in the satisfaction of self-actualization needs.

\subsection{Limitations}

Currently, the data we use to predict the well-being of Boston, MA and Kansas City, MO are based on city-wide information. For the purposes of this case study, we use city level data to simplify the discussion and to make a point regarding how the data are easily accessible. However, city level predictions come with the risk of generating numerical predictions that might be generalizing, undermining, or exaggerating the effect of some of the urban attributes and indicators. Alternatively, data based on a smaller geographic region, such as a county, district, or neighborhood would contribute greatly to fine-grain analysis and understanding of well-being in a local sense. A focus on a smaller location could help avoid the potential problems that might arise from applying the Well-Being Index on a city-wide level, which we raised earlier. For example, instead of studying the well-being of Boston as a whole, the Well-Being Index could be utilized to estimate and compare well-being in Boston's neighborhoods, such as Roxbury and Jamaica Plain, with differing socio-economic conditions and urban ecosystems.

\subsection{Recommendations for Future Research}

In addition to using data that are focused on a smaller region, we recommend using ethnographic approaches, such as interviews and fieldwork, to interact with community members and validate the 
results produced by the Well-Being Index. Because we use Numbeo's data, we involve some individual evaluation and reports of their well-being, but more qualitative methods could be taken to validate the scores for well-being. Further, qualitative approaches could clarify parts of the Well-Being Index that are insufficient and inform future improvements. Especially with regard to the evaluation of police presence, future research should consider reviewing a range of literature, from opinion editorials to academic publications, and additionally conversing with community members to place value on residents' opinions and reactions to police presence.

While the current Well-Being Index considers police presence and the Use of Force Policies that affect well-being, the Index requires further improvements by closely observing the governmental structures and specific policies that contribute to well-being. In future works, we hope to understand the impact of policies and regulations within urban environments to accurately capture the interplay between various power structures, urban policies, and well-being.

Currently, we are performing a linear calculation in order to generate scores for the urban attributes and indicators, by considering the minimum and maximum possible scores. The accuracy of the predictions could be improved by performing a more complex calculation that takes into account not only the minimum and maximum values, but also a standard of comparison, such as state or national averages and medians. Yigitcanlar and Lönnqvist's min-max normalization technique, which reflects the distribution of the indicator values and presents a relative scale according to the best and worst values, could be employed as a new weighing method [64].

\section{Conclusions}

Thus far, within the urban planning and design community and adjacent literature, research has studied well-being in relation to only a select few urban features. We recognize that not much research has established a complete study of various urban features that influence well-being from both subjective and objective lenses. Additionally, we have stressed how traditional objective indicators, such as GDP, are weak for measuring well-being. This is one of the main reasons why we conduct this research to reshape well-being indicators and establish a comprehensive set of well-being indicators that integrate subjective and objective indicators of well-being for our CityScope platform. We propose a Well-Being Index with five urban indicators that are based on urban attributes. The five urban indicators are Community Connectedness, Safety \& Security, Physical Health, Mental Health, and Diversity, and, together, they represent a comprehensive collection of urban features that affect well-being. For each urban attribute, we provide calculations to quantify its impact on well-being. Although our case study is based in the U.S., the Well-Being Index can be applied to any urban environment world-wide. The blend of subjective and objective indicators of well-being allows for the identification and consideration of various urban features that require attention and improvement. By applying the Well-Being Index to the CityScope platform, a diverse group of stakeholders can collaboratively make future decisions for urban planning and design by focusing on well-being.

Author Contributions: L.O. contributed to conceptualization, methodology, data collection, validation, resources, writing original draft. L.A. contributed to conceptualization, methodology, reviewing and editing, supervision, project administration. K.L. contributed to supervision, project administration. All authors have read and agreed to the published version of the manuscript.

Funding: This research received no external funding.

Acknowledgments: Research on this paper was supported by Nigel Jacob and Nayeli Rodriguez of New Urban Dynamics of the City of Boston, Leticia Izquierdo, and Numbeo.

Conflicts of Interest: The authors declare no conflict of interest.

\section{References}

1. United Nations. The World's Cities in 2018-Data Booklet; United Nations: New York, NY, USA, 2018.

2. Douglas, I. The Urban Environment; Edward Arnold Publishers Ltd: London, UK, 1983. 
3. McMichael, A.J. The urban environment and health in a world of increasing globalization: Issues for developing countries. Bull. World Health Organ. 2000, 78, 1117-1126. [PubMed]

4. Stansfeld, S.; Haines, M.; Brown, B. Noise and health in the urban environment. Rev. Environ. Health 2000, 15, 43-82. [CrossRef] [PubMed]

5. Galea, S.; Freudenberg, N.; Vlahov, D. Cities and population health. Soc. Sci. Med. 2005, 60, 1017-1033. [CrossRef]

6. Gill, S.E.; Handley, J.F.; Ennos, A.R.; Pauleit, S.; Theuray, N.; Lindley, S.J. Characterising the urban environment of UK cities and towns: A template for landscape planning. Landsc. Urban Plan. 2008, 87, 210-222. [CrossRef]

7. Ichimura, M. Urbanization, urban environment and land use: Challenges and opportunities. In Proceedings of the Asia-Pacific Forum for Environment and Development, Expert Meeting, Guilin, China, 23 January 2003; Volume 23.

8. Sch'affler, A.; Swilling, M. Valuing green infrastructure in an urban environment under pressure-The Johannesburg case. Ecol. Econ. 2013, 86, 246-257. [CrossRef]

9. Alonso, L.; Zhang, Y.R.; Grignard, A.; Noyman, A.; Sakai, Y.; ElKatsha, M.; Doorley, R.; Larson, K. Cityscope: CityScope: A Data-Driven Interactive Simulation Tool for Urban Design. Use Case Volpe. In International Conference on Complex Systems; Springer: Berlin, Germany, 2018; pp. 253-261.

10. Grignard, A.; Macià, N.; Alonso Pastor, L.; Noyman, A.; Zhang, Y.; Larson, K. Cityscope andorra: A multi-level interactive and tangible agent-based visualization. In Proceedings of the 17th International Conference on Autonomous Agents and MultiAgent Systems, Stockholm, Sweden, 10-15 July 2018; pp. 1939-1940.

11. Zhang, Y.; Larson, K. CityScope-Application of Tangible Interface, Augmented Reality, and Artificial Intelligence in the Urban Decision Support System. Time Archit. 2018.

12. Noyman, A.; Sakai, Y.; Larson, K. Cityscopear: Urban design and crowdsourced engagement platform. arXiv 2019, arXiv:1907.08586.

13. Stewart, A.F.; Zegras, P.C.; Tinn, P.; Rosenblum, J.L. Tangible Tools for Public Transportation Planning: Public Involvement and Learning for Bus Rapid Transit Corridor Design. Transp. Res. Rec. 2018, 2672, 785-795. [CrossRef]

14. Taillandier, P.; Grignard, A.; Marilleau, N.; Philippon, D.; Huynh, Q.N.; Gaudou, B.; Drogoul, A. Participatory Modeling and Simulation with the GAMA platform. J. Artif. Soc. Soc. Simul. 2019, 22. [CrossRef]

15. Alfeo, A.L.; Ferrer, E.C.; Carrillo, Y.L.; Grignard, A.; Pastor, L.A.; Sleeper, D.T.; Cimino, M.G.; Lepri, B.; Vaglini, G.; Larson, K.; et al. Urban Swarms: A new approach for autonomous waste management. In Proceedings of the 2019 International Conference on Robotics and Automation (ICRA), Montreal, QC, Canada, 20-24 May 2019; pp. 4233-4240.

16. Doorley, R.; Noyman, A.; Sakai, Y.; Larson, K. What's Your MoCho? Real-time Mode Choice Prediction Using Discrete Choice Models and a HCI Platform. In Proceedings of the UrbComp '19: 8th SIGKDD International Workshop on Urban Computing, Anchorage, AK, USA, 5 August 2019.

17. Marrocco, L.; Ferrer, E.C.; Bucchiarone, A.; Grignard, A.; Alonso, L.; Larson, K. Basic: Towards a blockchained agent-based simulator for cities. In Proceedings of the International Workshop on Massively Multiagent Systems, Stockholm, Sweden, 14 July 2018; Springer: Berlin, Germany, 2018; pp. 144-162.

18. Zhang, Y. CityMatrix: An Urban Decision Support System Augmented by Artificial Intelligence. Ph.D. Thesis, Massachusetts Institute of Technology, Cambridge, MA, USA, 2017.

19. Noyman, A.; Doorley, R.; Xiong, Z.; Alonso, L.; Grignard, A.; Larson, K. Reversed urbanism: Inferring urban performance through behavioral patterns in temporal telecom data. Environ. Plan. B Urban Anal. City Sci. 2019, 46, 1480-1498. [CrossRef]

20. Taillandier, P.; Gaudou, B.; Grignard, A.; Huynh, Q.N.; Marilleau, N.; Caillou, P.; Philippon, D.; Drogoul, A. Building, composing and experimenting complex spatial models with the GAMA platform. GeoInformatica 2019, 23, 299-322. [CrossRef]

21. Aubuchon, A.; Lyons, K.; Larson, K. Machine Learning for Real-time Urban Metrics and Design Recommendations. In Proceedings of the Association for Computer Aided Design in Architecture (ACADIA), Mexico City, Mexico, 18-20 October 2018.

22. Krefis, A.C.; Augustin, M.; Schlünzen, K.H.; Oßenbrügge, J.; Augustin, J. How does the urban environment affect health and well-being? A systematic review. Urban Sci. 2018, 2, 21. [CrossRef] 
23. Dodge, R.; Daly, A.P.; Huyton, J.; Sanders, L.D. The challenge of defining wellbeing. Int. J. Wellbeing $2012,2$. [CrossRef]

24. Crisp, R. Well-Being. In The Stanford Encyclopedia of Philosophy, Fall 2017 ed.; Zalta, E.N., Ed.; Metaphysics Research Lab, Stanford University: Stanford, CA, USA, 2017.

25. Oswald, A.J.; Wu, S. Objective confirmation of subjective measures of human well-being: Evidence from the USA. Science 2010, 327, 576-579. [CrossRef]

26. Zinsstag, J.; Schelling, E.; Waltner-Toews, D.; Tanner, M. From “one medicine" to "one health" and systemic approaches to health and well-being. Prev. Vet. Med. 2011, 101, 148-156. [CrossRef] [PubMed]

27. Sirgy, M.J. The Psychology of Quality of Life: Hedonic Well-Being, Life Satisfaction, and Eudaimonia; Springer Science \& Business Media: Berlin, Germany, 2012; Volume 50.

28. Maslow, A.H. Motivation and Personality; Prabhat Prakashan: New Delhi, India, 1981.

29. Diener, E.; Emmons, R.A.; Larsen, R.J.; Griffin, S. The satisfaction with life scale. J. Personal. Assess. 1985, 49, 71-75. [CrossRef]

30. Mehan, A.; Soflaei, F. Social sustainability in urban context: Concepts, definitions, and principles. In Architectural Research Addressing Societal Challenges-Couceiro da Costa, et al. (Eds); CRC Press: Cleveland, OH, USA, 2017; pp. 293-299.

31. Western, M.; Tomaszewski, W. Subjective wellbeing, objective wellbeing and inequality in Australia. PLoS ONE 2016, 11, e0163345. [CrossRef] [PubMed]

32. Pacione, M. Urban environmental quality and human wellbeing-A social geographical perspective. Landsc. Urban Plan. 2003, 65, 19-30. [CrossRef]

33. Diener, E. Subjective well-being. In The Science of Well-Being; Springer: Berlin, Germany, 2009; pp. 11-58.

34. Veenhoven, R. Sociological theories of subjective well-being. Sci. Subj. Well-Being 2008, 9, 44-61.

35. Carrus, G.; Scopelliti, M.; Lafortezza, R.; Colangelo, G.; Ferrini, F.; Salbitano, F.; Agrimi, M.; Portoghesi, L.; Semenzato, P.; Sanesi, G. Go greener, feel better? The positive effects of biodiversity on the well-being of individuals visiting urban and peri-urban green areas. Landsc. Urban Plan. 2015, 134, 221-228. [CrossRef]

36. Mao, Y.; Fornara, F.; Manca, S.; Bonnes, M.; Bonaiuto, M. Perceived Residential Environment Quality Indicators and neighborhood attachment: A confirmation study on a Chinese sample in Chongqing. PsyCh J. 2015, 4, 123-137. [CrossRef] [PubMed]

37. Bonaiuto, M.; Fornara, F.; Alves, S.; Ferreira, I.; Mao, Y.; Moffat, E.; Piccinin, G.; Rahimi, L. Urban environment and well-being: Cross-cultural studies on Perceived Residential Environment Quality Indicators (PREQIs). Cogn. Process. 2015, 16, 165-169. [CrossRef] [PubMed]

38. OECD Better Life Index. How's Life? 2020 Measuring Well-Being; OECD Publishing: Paris, France, 2020.

39. The Commission on Measuring Well-being. Measuring National Well-Being-Proposed Well-Being Indicator; University of Sussex: Brighton, UK, 2011.

40. Voukelatou, V.; Gabrielli, L.; Miliou, I.; Cresci, S.; Sharma, R.; Tesconi, M.; Pappalardo, L. Measuring objective and subjective well-being: Dimensions and data sources. Int. J. Data Sci. Anal. 2020, 1-31. [CrossRef]

41. Frey, B.S.; Stutzer, A. What can economists learn from happiness research? J. Econ. Lit. 2002, 40, 402-435. [CrossRef]

42. Pretty, J.; Griffin, M.; Sellens, M.; Pretty, C. Green Exercise: Complementary Roles of Nature, Exercise and Diet in Physical and Emotional Well-Being and Implications for Public Health Policy. CES Occas. Pap. 2003, 1, 1-39.

43. Kent, J.L.; Thompson, S. The three domains of urban planning for health and well-being. J. Plan. Lit. 2014, 29, 239-256. [CrossRef]

44. Twiss, J.; Dickinson, J.; Duma, S.; Kleinman, T.; Paulsen, H.; Rilveria, L. Community gardens: Lessons learned from California healthy cities and communities. Am. J. Public Health 2003, 93, 1435-1438. [CrossRef] [PubMed]

45. Hynes, H.P.; Howe, G. Urban horticulture in the contemporary United States: Personal and community benefits. Int. Conf. Urban Hortic. 2002, 171-181. [CrossRef]

46. Matsuoka, R.H.; Kaplan, R. People needs in the urban landscape: Analysis of landscape and urban planning contributions. Landsc. Urban Plan. 2008, 84, 7-19. [CrossRef]

47. Liu, H.L.; Shen, Y.S. The impact of green space changes on air pollution and microclimates: A case study of the Taipei metropolitan area. Sustainability 2014, 6, 8827-8855. [CrossRef] 
48. Wilby, R.L.; Perry, G.L. Climate change, biodiversity and the urban environment: A critical review based on London, UK. Prog. Phys. Geogr. 2006, 30, 73-98. [CrossRef]

49. Leung, D.Y. Outdoor-indoor air pollution in urban environment: Challenges and opportunity. Front. Environ. Sci. 2015, 2, 69. [CrossRef]

50. Babisch, W.; Wolf, K.; Petz, M.; Heinrich, J.; Cyrys, J.; Peters, A. Associations between traffic noise, particulate air pollution, hypertension, and isolated systolic hypertension in adults: The KORA study. Environ. Health Perspect. 2014, 122, 492-498. [CrossRef]

51. Gidlöf-Gunnarsson, A.; Öhrström, E. Noise and well-being in urban residential environments: The potential role of perceived availability to nearby green areas. Landsc. Urban Plan. 2007, 83, 115-126. [CrossRef]

52. Wakefield, S.; Yeudall, F.; Taron, C.; Reynolds, J.; Skinner, A. Growing urban health: Community gardening in South-East Toronto. Health Promot. Int. 2007, 22, 92-101. [CrossRef] [PubMed]

53. Armstrong, D. A survey of community gardens in upstate New York: Implications for health promotion and community development. Health Place 2000, 6, 319-327. [CrossRef]

54. Taylor, L.; Hochuli, D.F. Creating better cities: How biodiversity and ecosystem functioning enhance urban residents' wellbeing. Urban Ecosyst. 2015, 18, 747-762. [CrossRef]

55. Barton, J.; Pretty, J. What is the best dose of nature and green exercise for improving mental health? A multi-study analysis. Environ. Sci. Technol. 2010, 44, 3947-3955. [CrossRef]

56. Carter, M.; Horwitz, P. Beyond proximity: The importance of green space useability to self-reported health. EcoHealth 2014, 11, 322-332. [CrossRef]

57. Mitchell, R. Is physical activity in natural environments better for mental health than physical activity in other environments? Soc. Sci. Med. 2013, 91, 130-134. [CrossRef]

58. McCracken, D.S.; Allen, D.A.; Gow, A.J. Associations between urban greenspace and health-related quality of life in children. Prev. Med. Rep. 2016, 3, 211-221. [CrossRef] [PubMed]

59. Fretwell, K.; Greig, A. Towards a better understanding of the relationship between individual's self-reported connection to nature, personal well-being and environmental awareness. Sustainability 2019, 11, 1386. [CrossRef]

60. Hartig, T.; Evans, G.W.; Jamner, L.D.; Davis, D.S.; Gärling, T. Tracking restoration in natural and urban field settings. J. Environ. Psychol. 2003, 23, 109-123. [CrossRef]

61. Yigitcanlar, T.; Velibeyoglu, K. Knowledge-based urban development: The local economic development path of Brisbane, Australia. Local Econ. 2008, 23, 195-207. [CrossRef]

62. Rittgasszer, I. Knowledge-based Urban Development, as a New Development Paradigm. In Regional Growth, Development and Competitiveness; University of Szeged: Szeged, Hungary, 2013; pp. 36-46.

63. Yigitcanlar, T.; O'Connor, K.; Westerman, C. The making of knowledge cities: Melbourne's knowledge-based urban development experience. Cities 2008, 25, 63-72. [CrossRef]

64. Yigitcanlar, T.; Lönnqvist, A. Benchmarking knowledge-based urban development performance: Results from the international comparison of Helsinki. Cities 2013, 31, 357-369. [CrossRef]

65. The Global Youth Wellbeing Index. Available online: https://www.youthindex.org/ (accessed on 30 September 2020).

66. Gallup. How does the U.S. Gallup-Sharecare Well-Being Index Work? Available online: https://news. gallup.com/poll/128186/gallup-healthways-index-work.aspx (accessed on 30 September 2020).

67. Australian Centre on Quality of Life. Personal Wellbeing Index-Adult(PWI-A). Available online: http:/ / www.acqol.com.au/instruments (accessed on 30 September 2020).

68. European Social Survey. Measuring and Reporting on Europeans' Wellbeing: Findings form the European Social Survey; European Social Survey: London, UK, 2015.

69. Alterman, T.; Tsai, R.; Ju, J.; Kelly, K.M. Trust in the Work Environment and Cardiovascular Disease Risk: Findings from the Gallup-Sharecare Well-Being Index. Int. J. Environ. Res. Public Health 2019, 16, 230. [CrossRef]

70. Larson, L.R.; Jennings, V.; Cloutier, S.A. Public parks and wellbeing in urban areas of the United States. PLoS ONE 2016, 11, e0153211. [CrossRef]

71. Edahiro, J. Creating Well-being Indicators of Japan, by Japan, for Japan. JFS Jpn. Sustain. (126). Available online: https: / / www.japanfs.org/en/news/archives/news_id032635.html (accessed on 30 September 2020).

72. Gan, X.; Fernandez, I.C.; Guo, J.; Wilson, M.; Zhao, Y.; Zhou, B.; Wu, J. When to use what: Methods for weighting and aggregating sustainability indicators. Ecol. Indic. 2017, 81, 491-502. [CrossRef] 
73. Simpson, E.H. Measurement of diversity. Nature 1949, 163, 688. [CrossRef]

74. Lima, A.; Melnik, M. Boston: Measuring Diversity in a Changing City; Boston Redevelopment Agency: Boston, MA, USA, 2010.

75. Jansson, M.; Fors, H.; Lindgren, T.; Wiström, B. Perceived personal safety in relation to urban woodland vegetation-A review. Urban For. Urban Green. 2013, 12, 127-133. [CrossRef]

76. Jiang, B.; Mak, C.N.S.; Zhong, H.; Larsen, L.; Webster, C.J. From broken windows to perceived routine activities: Examining impacts of environmental interventions on perceived safety of urban alleys. Front. Psychol. 2018, 9, 2450. [CrossRef] [PubMed]

77. Loewen, L.J.; Steel, G.D.; Suedfeld, P. Perceived safety from crime in the urban environment. J. Environ. Psychol. 1993, 13, 323-331. [CrossRef]

78. McCormack, G.R.; Rock, M.; Toohey, A.M.; Hignell, D. Characteristics of urban parks associated with park use and physical activity: A review of qualitative research. Health Place 2010, 16, 712-726. [CrossRef]

79. Ferré, M.B.; Guitart, A.O.; Ferret, M.P. Children and playgrounds in Mediterranean cities. Child. Geogr. 2006, 4, 173-183. [CrossRef]

80. Tucker, P.; Gilliland, J.; Irwin, J.D. Splashpads, swings, and shade. Can. J. Public Health 2007, 98, $198-202$. [CrossRef]

81. Gearin, E.; Kahle, C. Teen and adult perceptions of urban green space Los Angeles. Child. Youth Environ. 2006, 16, 25-48.

82. Wilbur, J.; Chandler, P.; Dancy, B.; Choi, J.; Plonczynski, D. Environmental, policy, and cultural factors related to physical activity in urban, African American women. Women Health 2002, 36, 17-28. [CrossRef]

83. Ries, A.V.; Gittelsohn, J.; Voorhees, C.C.; Roche, K.M.; Clifton, K.J.; Astone, N.M. The environment and urban adolescents' use of recreational facilities for physical activity: A qualitative study. Am. J. Health Promot. 2008, 23, 43-50. [CrossRef]

84. Spangler-Murphy, E.; Krummel, D.A.; Morrison, N.; Gordon, P.M. Environmental perceptions related to physical activity in high-and low-risk counties. Health Promot. Pract. 2005, 6, 57-63. [CrossRef]

85. Chivite-Matthews, N.; Maggs, P. Crime, Policing and Justice: The Experience of Older People. Findings from the British Crime Survey, England and Wales; Home Office: London, UK, 2002.

86. Berry, H.L. 'Crowded suburbs' and 'killer cities': A brief review of the relationship between urban environments and mental health. N. S. W. Public Health Bull. 2008, 18, 222-227. [CrossRef] [PubMed]

87. D'Alessandro, D.; Buffoli, M.; Capasso, L.; Fara, G.M.; Rebecchi, A.; Capolongo, S. Green areas and public health: Improving wellbeing and physical activity in the urban context. Epidemiol. Prev. 2015, 39, 8-13. [PubMed]

88. Franzini, L.; Caughy, M.; Spears, W.; Esquer, M.E.F. Neighborhood economic conditions, social processes, and self-rated health in low-income neighborhoods in Texas: A multilevel latent variables model. Soc. Sci. Med. 2005, 61, 1135-1150. [CrossRef] [PubMed]

89. Timperio, A.; Crawford, D.; Telford, A.; Salmon, J. Perceptions about the local neighborhood and walking and cycling among children. Prev. Med. 2004, 38, 39-47. [CrossRef] [PubMed]

90. Smith, N.R.; Lewis, D.J.; Fahy, A.; Eldridge, S.; Taylor, S.J.; Moore, D.G.; Clark, C.; Stansfeld, S.A.; Cummins, S. Individual socio-demographic factors and perceptions of the environment as determinants of inequalities in adolescent physical and psychological health: The Olympic Regeneration in East London (ORiEL) study. BMC Public Health 2015, 15, 150. [CrossRef]

91. Stafford, M.; Chandola, T.; Marmot, M. Association between fear of crime and mental health and physical functioning. Am. J. Public Health 2007, 97, 2076-2081. [CrossRef]

92. Davidson, M.M.; Butchko, M.S.; Robbins, K.; Sherd, L.W.; Gervais, S.J. The mediating role of perceived safety on street harassment and anxiety. Psychol. Violence 2016, 6, 553. [CrossRef]

93. Baba, C.; Kearns, A.; McIntosh, E.; Tannahill, C.; Lewsey, J. Is empowerment a route to improving mental health and wellbeing in an urban regeneration (UR) context? Urban Stud. 2017, 54, 1619-1637. [CrossRef]

94. Bond, L.; Kearns, A.; Mason, P.; Tannahill, C.; Egan, M.; Whitely, E. Exploring the relationships between housing, neighbourhoods and mental wellbeing for residents of deprived areas. BMC Public Health 2012, 12, 48. [CrossRef]

95. Wang, R.; Yuan, Y.; Liu, Y.; Zhang, J.; Liu, P.; Lu, Y.; Yao, Y. Using street view data and machine learning to assess how perception of neighborhood safety influences urban residents' mental health. Health Place 2019, 59, 102186. [CrossRef] [PubMed] 
96. Numbeo. About Crime Indices at This Website. Available online: https://www.numbeo.com/crime/ indices_explained.jsp (accessed on 30 September 2020).

97. Kuo, F.E.; Sullivan, W.C.; Coley, R.L.; Brunson, L. Fertile ground for community: Inner-city neighborhood common spaces. Am. J. Community Psychol. 1998, 26, 823-851. [CrossRef]

98. Kaźmierczak, A. The contribution of local parks to neighbourhood social ties. Landsc. Urban Plan. 2013, 109, 31-44. [CrossRef]

99. Arnberger, A.; Eder, R. The influence of green space on community attachment of urban and suburban residents. Urban For. Urban Green. 2012, 11, 41-49. [CrossRef]

100. Talen, E. Sense of community and neighbourhood form: An assessment of the social doctrine of new urbanism. Urban Stud. 1999, 36, 1361-1379. [CrossRef]

101. Hur, M.; Nasar, J.L.; Chun, B. Neighborhood satisfaction, physical and perceived naturalness and openness. J. Environ. Psychol. 2010, 30, 52-59. [CrossRef]

102. Müderrisoğlu, H.; Demir, Z. The relationship between perceived beauty and safety in urban recreation parks. J. Appl. Sci. 2004, 4, 72-77. [CrossRef]

103. The Trust for Public Land. 2018. Available online: https:/ /www.tpl.org/parkscore (accessed on 30 September 2020).

104. Peters, K.; Elands, B.; Buijs, A. Social interactions in urban parks: Stimulating social cohesion? Urban For. Urban Green. 2010, 9, 93-100. [CrossRef]

105. Kweon, B.S.; Sullivan, W.C.; Wiley, A.R. Green common spaces and the social integration of inner-city older adults. Environ. Behav. 1998, 30, 832-858. [CrossRef]

106. Maas, J.; Van Dillen, S.M.; Verheij, R.A.; Groenewegen, P.P. Social contacts as a possible mechanism behind the relation between green space and health. Health Place 2009, 15, 586-595. [CrossRef] [PubMed]

107. Coombes, E.; Jones, A.P.; Hillsdon, M. The relationship of physical activity and overweight to objectively measured green space accessibility and use. Soc. Sci. Med. 2010, 70, 816-822. [CrossRef] [PubMed]

108. Richardson, E.A.; Pearce, J.; Mitchell, R.; Kingham, S. Role of physical activity in the relationship between urban green space and health. Public Health 2013, 127, 318-324. [CrossRef] [PubMed]

109. Tzoulas, K.; Korpela, K.; Venn, S.; Yli-Pelkonen, V.; Kaźmierczak, A.; Niemela, J.; James, P. Promoting ecosystem and human health in urban areas using Green Infrastructure: A literature review. Landsc. Urban Plan. 2007, 81, 167-178. [CrossRef]

110. De Vries, S.; Verheij, R.A.; Groenewegen, P.P.; Spreeuwenberg, P. Natural environments-Healthy environments? An exploratory analysis of the relationship between greenspace and health. Environ. Plan. A 2003, 35, 1717-1731. [CrossRef]

111. Yang, Y.; Diez-Roux, A.V. Walking distance by trip purpose and population subgroups. Am. J. Prev. Med. 2012, 43, 11-19. [CrossRef]

112. Doorley, R.; Alonso, L.; Noyman, A.; Wang, C.; Jara-Figueroa, C.; Girgnard, A.; Sakai, Y.; Larson, K. MIT-Ford Corktown Urban Performance Project: Methodology Report; Technical report; MIT Media Lab City Science Group: Cambridge, MA, USA, 2020.

113. Lennon, M.; Douglas, O.; Scott, M. Urban green space for health and well-being: Developing an 'affordances' framework for planning and design. J. Urban Des. 2017, 22, 778-795. [CrossRef]

114. Jung, E.; Lee, J.; Kim, K. The relationship between pedestrian environments and sense of community in apartment complexes in Seoul, Korea. J. Asian Archit. Build. Eng. 2015, 14, 411-418. [CrossRef]

115. Williams, P.; Pocock, B. Building 'community'for different stages of life: Physical and social infrastructure in master planned communities. Community Work. Fam. 2010, 13, 71-87. [CrossRef]

116. Oldenburg, R.; Brissett, D. The third place. Qual. Sociol. 1982, 5, 265-284. [CrossRef]

117. Richard, L.; Gauvin, L.; Gosselin, C.; Laforest, S. Staying connected: Neighbourhood correlates of social participation among older adults living in an urban environment in Montreal, Quebec. Health Promot. Int. 2009, 24, 46-57. [CrossRef]

118. Walk Score. 2020. Available online: http://www.walkscore.com/methodology.shtml (accessed on 30 September 2020).

119. Duncan, D.T.; Aldstadt, J.; Whalen, J.; White, K.; Castro, M.C.; Williams, D.R. Space, race, and poverty: Spatial inequalities in walkable neighborhood amenities? Demogr. Res. 2012, 26, 409. [CrossRef] [PubMed]

120. Duncan, D.T.; Aldstadt, J.; Whalen, J.; Melly, S.J.; Gortmaker, S.L. Validation of Walk Score ${ }^{\circledR}$ for estimating neighborhood walkability: An analysis of four US metropolitan areas. Int. J. Environ. Res. Public Health 2011, 8, 4160-4179. [CrossRef] [PubMed] 
121. Carr, L.J.; Dunsiger, S.I.; Marcus, B.H. Walk score ${ }^{\mathrm{TM}}$ as a global estimate of neighborhood walkability. Am. J. Prev. Med. 2010, 39, 460-463. [CrossRef] [PubMed]

122. Bartolomei, L.; Corkery, L.; Judd, B.; Thompson, S. A Bountiful Harvest: Community Gardens and Neighbourhood Renewal in Water Loo; New South Wales Government-Department of Housing-University of New South Wales: Kensington, Australia, 2003.

123. Holland, L. Diversity and connections in community gardens: A contribution to local sustainability. Local Environ. 2004, 9, 285-305. [CrossRef]

124. Macias, T. Working toward a just, equitable, and local food system: The social impact of Community-Based agriculture. Soc. Sci. Q. 2008, 89, 1086-1101. [CrossRef]

125. Irvine, S.; Johnson, L.; Peters, K. Community gardens and sustainable land use planning: A case-study of the Alex Wilson community garden. Local Environ. 1999, 4, 33-46. [CrossRef]

126. Kaplan, R. Some Psycholog Ical Benefits of Gardening. Environ. Behav. 1973, 5, 145-162. [CrossRef]

127. Thompson, S.; Corkery, L.; Judd, B. The role of community gardens in sustaining healthy communities. In Proceedings of the Third State of Australian Cities Conference, Adelaide, Australia, 28-30 November 2007.

128. Thompson, C.W.; Roe, J.; Aspinall, P.; Mitchell, R.; Clow, A.; Miller, D. More green space is linked to less stress in deprived communities: Evidence from salivary cortisol patterns. Landsc. Urban Plan. 2012, 105, 221-229. [CrossRef]

129. Van Den Berg, A.E.; Custers, M.H. Gardening promotes neuroendocrine and affective restoration from stress. J. Health Psychol. 2011, 16, 3-11. [CrossRef]

130. Freelon, D.; McIlwain, C.D.; Clark, M. Beyond the hashtags:\# Ferguson,\# Blacklivesmatter, and the online struggle for offline justice. In Center for Media \& Social Impact, American University, Forthcoming; American University School of Communication: Washington, DC, USA, 2016.

131. Williamson, V.; Trump, K.S.; Einstein, K.L. Black lives matter: Evidence that police-caused deaths predict protest activity. Perspect. Politics 2018, 16, 400-415. [CrossRef]

132. Dunham, R.G.; Petersen, N. Making Black lives matter: Evidence-based policies for reducing police bias in the use of deadly force. Criminol. Pub. Pol'y 2017, 16, 341. [CrossRef]

133. Mapping Police Violence. 2020. Available online: mappingpoliceviolence.org (accessed on 30 September 2020).

134. Police Use of Force Project. Available online: http:/ / useofforceproject.org/ (accessed on 30 September 2020).

135. Miles, R.; Coutts, C.; Mohamadi, A. Neighborhood urban form, social environment, and depression. J. Urban Health 2012, 89, 1-18. [CrossRef] [PubMed]

136. U.S. Census Bureau. American Community Survey, 2019. Available online: https://data.census.gov/cedsci/ (accessed on 30 September 2020).

137. Becker, W.; Saisana, M.; Paruolo, P.; Vandecasteele, I. Weights and importance in composite indicators: Closing the gap. Ecol. Indic. 2017, 80, 12-22. [CrossRef] [PubMed]

138. Nardo, M.; Saisana, M.; Saltelli, A.; Tarantola, S. Tools for composite indicators building. Eur. Com. Ispra 2005, 15, 19-20.

139. MIT Media Lab City Science Group. City Science Network. Available online: https://www.media.mit.edu/ projects / city-science-network/overview/ (accessed on 30 September 2020).

140. Mehta, V. Look closely and you will see, listen carefully and you will hear: Urban design and social interaction on streets. J. Urban Des. 2009, 14, 29-64. [CrossRef]

141. Roffey, S. Inclusive and exclusive belonging: The impact on individual and community wellbeing. Educ. Child Psychol. 2013, 30, 38-49.

142. Alnaji, L.; Askari, M.Y.; Refae, G.A.E. Can tolerance of diverse groups improve the wellbeing of societies? Int. J. Econ. Bus. Res. 2016, 11, 48-57. [CrossRef]

Publisher's Note: MDPI stays neutral with regard to jurisdictional claims in published maps and institutional affiliations.

(C) 2020 by the authors. Licensee MDPI, Basel, Switzerland. This article is an open access article distributed under the terms and conditions of the Creative Commons Attribution (CC BY) license (http:// creativecommons.org/licenses/by/4.0/). 